\title{
Self Reported Dental Health Attitudes and Behaviour of Dental Students in Turkey
}

Sinem Yildiz

Basak Dogan

\section{ABSTRACT}

Objectives: The aim of this study was to compare the differences in self-reported oral health attitudes and behaviour between preclinical and clinical dental students in Turkey using Hiroshima University Dental Behavioural Inventory (HU-DBI).

Methods: A Turkish version HU-DBI questionnaire with additional 7 questions, totally 27 items, was distributed among 1022 dental students.

Results: The response rate was $75 \%$ (486 preclinical and 278 clinical students). Significantly higher $(P=0.000)$ percentage of the preclinical students, compared to clinical students, worry about colour of their teeth, are bothered by the colour of their gums, put off going to the dentist until they have a toothache; think that their teeth are getting worse despite their daily brushing, it is impossible to prevent gum disease with tooth brushing alone, and they cannot help having false teeth when they are old. Moreover, the preclinical students more frequently agree on that their gums tend to bleed when they brush their teeth, they use a toothbrush which has hard bristles, and they don't feel they've brushed well unless with strong strokes $(P=0.000)$. However, a higher proportion of clinical students compared to preclinical students brush each of their teeth carefully, think that they can clean their teeth without using toothpaste, have had their dentist tell them that they brush very well $(P=0.000)$. The HU-DBI score of clinical students $(7.47 \pm 1.86)$ was significantly $(P=0.000)$ higher than preclinical students $(6.00 \pm 1.86)$.

Conclusions: Dental students should have a comprehensive program, including their self-care regimes, starting from their first year of education. (Eur J Dent 2011;5:253-259)

Key words: Dental students; Oral health attitudes and behavior; HU-DBI; Turkey.

\section{INTRODUCTION}

Written and visual media, and dentists are the most common sources for receiving oral health information. ${ }^{1,2}$ Oral health attitudes and behaviour are also influenced by parents in early years

a Marmara University, Faculty of Dentistry, Department of Periodontology, Istanbul, Turkey.

- Corresponding author: Basak Dogan Marmara University, Faculty of Dentistry, Department of Periodontology Buyuk Ciftlik Sokak No:6 34365 Nisantasi, Sisli, Istanbul, Turkey.

Phone: +90212 2319120

Fax: +902122465247

E-mail: basakdoganamarmara.edu.tr of life ${ }^{3,4}$ and predict the actual oral health status. ${ }^{5}$ Dental students, as the future providers of dental care, are expected to be a role model for their patients, family members and friends and ensure their awareness of oral health maintenance. Attitudes of dental students toward their own oral health affect their oral health habits and also have possible influence on the improvement of the oral health of their patients. ${ }^{6,7}$

Hiroshima University Dental Behavioural Inventory (HU-DBI) was developed by Kawamura dealing mainly with oral health attitudes and be- 
haviour of patients in tooth brushing. ${ }^{8}$ It has first been administered in Japan and demonstrated to be a useful instrument in understanding the perceptions of patients and oral health behaviour. Then it has been used for evaluating the differences in oral health behaviours between dental students from different countries due to the curriculum dissimilarities of dental schools ${ }^{9-11}$ and variety between the cultures. ${ }^{11,12}$ There are also several studies on gender differences. ${ }^{13-20}$ Previous studies on dental students, which mostly majored on the comparison of the first and advanced years of education, showed that the final year dental students had significant improvements in oral hygiene practices, attitudes and behaviour. ${ }^{11,13,20-22}$ As far as to our knowledge, there are very few studies comparing preclinical and clinical students with inconsistent results. ${ }^{19,23}$

The aim of this study was to compare the differences in self-reported oral health attitudes and behaviour between preclinical and clinical dental students in Turkey using HU-DBI.

\section{MATERIALS AND METHODS}

The HU-DBI is a 20 -item questionnaire in dichotomous response format (agree/disagree). The original $\mathrm{HU}-\mathrm{DBI}$ questionnaire was written in Japanese. Turkish translation of the $\mathrm{HU}-\mathrm{DBI}^{20}$ and additional 7 items was used in this study (Table 1 , items 21 to 27). The translation was discussed with two Turkish bilinguists. Back-translation was used during the translation process. After minor changes were made, data for testing the validity of selfrating scales were collected from a convenience sample of 26 bilinguists (mean age $36.23 \pm 6.83$ ). Bilinguists were asked to answer each version of the questionnaire separately at different times la week apart). The reliability of the translated version was measured using Cohen's Kappa. Kappa coefficient of the each 20 items was 1.0 .

Three of 6 old public dental faculties (being in dental education more than 40 years), University of Marmara and Istanbul (both in Istanbul), and University of Gazi (in Ankara) were included in this study. The questionnaire was distributed among 1022 dental students from all five academic years from three dental faculties at the beginning of the academic year 2005-2006. On the day of survey, at the end of a lecture, the questionnaire was distributed among all students present in the class. The students were informed that the participation in this study was voluntary base. Students willing to complete the questionnaire remained in the class. The inclusion criteria were, $i$ ) to response all the questions of the inventory, $i$ ) to state gender and date of birth.

First 3 years of dental education was preclinical and last 2 years were clinical years. Among 1022 dental students 1667 preclinical and 355 clinical students), 842 (82\%) (544 preclinical and 298 clinical students) were willing to participate (the response rate of the preclinical students was $82 \%$ and the clinical students was $84 \%$ ) and 764 $(75 \%)$ of them were included in the study. Out of 764 students, $486(64 \%)$ were preclinical $189 \%$ of the responded preclinical students) and 278 (36\%) were clinical $193 \%$ of the responded clinical students) students. Distribution of the students by the level of dental education, gender and mean age is shown in Table 2.

When calculating the HU-DBI scores; one point was given for each of agree responses to the items $4,9,11,12,16,19$ and one point was given for each of disagree response to the items $2,6,8,10,14$, 15. Maximum HU-DBI score was 12. Higher scores signify better oral behaviour. ${ }^{8}$

\section{Statistical analysis}

The SPSS version 15.0 was used for performing statistical analyses throughout the study. The Chi-square test was used for categorical data and Mann-Whitney U test for ordinal level data. Backward stepwise regression was carried out on the dependent variables (level of education and gender). Statistically significance was based on probability values of equal or less than 0.05 .

\section{RESULTS}

Table 1 shows the items of the HU-DBI and Table 3 shows the percentage distribution of the students with agree response by the level of education. Significant differences $(P<.01)$ were found for 18 of 27 items between the preclinical and the clinical students and described in detail under in following sections.

\section{Oral health attitudes}

The preclinical students were more frequently worrying about colour of their teeth $(39 \%)$ and gums $(25 \%)$ compared to the clinical students 
$121 \%$ and $13 \%$, respectively; $P \leq .001$ and $P<.001$, respectively). The proportion of the preclinical students who believed that having false teeth was inevitable $(30 \%)$ was significantly higher than the clinical students $(10 \%)(P<.001)$. Moreover, $43 \%$

Table 1. Questionnaire items of the HU-DBI. In the calculation of HU-DBI: (A): One point is given for each of these agree responses, (D): One point is given for each of these disagree responses.

\begin{tabular}{|c|c|}
\hline Item No. & Item descriptions \\
\hline 1 & I don't worry much about visiting the dentist \\
\hline 2 & My gums tend to bleed when I brush my teeth (D) \\
\hline 3 & I worry about colour of my teeth \\
\hline 4 & I have noticed some white sticky deposits on my teeth (A) \\
\hline 5 & I use a child-sized toothbrush \\
\hline 6 & $\begin{array}{l}\text { I think that I cannot help having false teeth when } \\
\text { I am old (D) }\end{array}$ \\
\hline 7 & I am bothered by the colour of my gums \\
\hline 8 & $\begin{array}{l}\text { I think my teeth are getting worse despite my daily } \\
\text { brushing (D) }\end{array}$ \\
\hline 9 & I brush each of my teeth carefully (A) \\
\hline 10 & I have never been professionally taught how to brush (D) \\
\hline 11 & I think I can clean my teeth without using toothpaste (A) \\
\hline 12 & I often check my teeth in a mirror after brushing $(A)$ \\
\hline 13 & I worry about having bad breath \\
\hline 14 & $\begin{array}{l}\text { It is impossible to prevent gum disease with toothbrush- } \\
\text { ing alone (D) }\end{array}$ \\
\hline 15 & I put off going to the dentist until I have a toothache (D) \\
\hline 16 & I have used a dye to see how clean my teeth are $(A)$ \\
\hline 17 & I use a toothbrush which has hard bristles \\
\hline 18 & $\begin{array}{l}\text { I don't feel l've brushed well unless I brush with strong } \\
\text { strokes }\end{array}$ \\
\hline 19 & $\begin{array}{l}\text { I feel I sometimes take too much time to brush my teeth } \\
\text { (A) }\end{array}$ \\
\hline 20 & I have had my dentist tell me that I brush very well \\
\hline 21 & I am satisfied with the appearance of my teeth \\
\hline 22 & I brush my teeth twice daily or more \\
\hline 23 & I use dental floss on regular basis everyday \\
\hline 24 & I use mouthwash on regular basis \\
\hline 25 & I smoke cigarettes \\
\hline 26 & I smoke more than $1 / 2$ pack per day \\
\hline 27 & I have been smoking for more than one year \\
\hline
\end{tabular}

of the clinical students believed that there was no need to use a toothpaste, while significantly lower proportion of the preclinical students (28\%) believed so $(P<.001)$. Although the preclinical students were significantly $(P<.001)$ more likely to believe that it was impossible to prevent gum disease with tooth brushing alone (70\%), the percentage of agree response to this item (Item 14) among the clinical students was still high (51\%).

\section{Oral health behaviour}

The clinical students were more likely to brush their teeth carefully $(76 \%)$ than the preclinical students $(61 \%),(P<.001)$. The clinical students were significantly $(P<.01)$ less likely to use a hard bristled toothbrush (15\%) than the preclinical students $(24 \%)$ and while $32 \%$ of the preclinical students brushed with strong strokes, $17 \%$ of the clinical students did so $(P<.001)$. Despite the significant increase in flossing behaviour during their dental education, only $19 \%$ of the preclinical and $31 \%$ of the clinical students used dental floss daily $(P<.001)$. Smoking behaviour was significantly $(P<.01)$ higher among the clinical students $(33 \%)$ than the preclinical students (22\%). From those who smoke cigarettes, $64 \%$ of the preclinical students and $85 \%$ of the clinical students smoked more than half pack per day $(\mathrm{P}<.001)$. In addition, $88 \%$ of the preclinical and $99 \%$ of the clinical dental students who smoke had been smoking for more than one year $(P<.001)$.

Majority of the dental students brushed their teeth twice daily or more (74\%), often checked their teeth after brushing (83\%) and worried about having bad breath (76\%) (Table 3 ).

Self-reported oral health and dental visits

One fourth of the preclinical students reported gum bleeding while $13 \%$ of the clinical ones did so $(P<.001)$. Besides, almost half of the preclini-

Table 2. Distribution of the students by academic year and gender.

\begin{tabular}{lcccc}
\hline Academic Year & No. of male students $(\%)$ & No. of female students (\%) & Total no. of students (\%) & Mean age \pm SD \\
\hline 1 & $94(56 \%)$ & $73(44 \%)$ & $167(21.8)$ & $19.75 \pm 0.98$ \\
2 & $73(46 \%)$ & $87(54 \%)$ & $160(20.9)$ & $20.69 \pm 0.82$ \\
3 & $98(62 \%)$ & $61(38 \%)$ & $159(20.8)$ & $21.95 \pm 1.95$ \\
4 & $106(61 \%)$ & $68(39 \%)$ & $174(22.7)$ & $22.87 \pm 1.29$ \\
5 & $57(55 \%)$ & $47(45 \%)$ & $104(13.6)$ & $24.13 \pm 1.38$ \\
Total & $428(56 \%)$ & $336(44 \%)$ & $764(100 \%)$ & $21.71 \pm 1.98$ \\
\hline
\end{tabular}

SD: Standard deviation 
cal students, but $(25 \%)$ of the clinical ones had never taken oral hygiene instructions professionally $(P<.001)$. The preclinical students were significantly $(P<.001)$ more often consulting a dentist when they only had a toothache $(47 \%)$ than the clinical students (28\%).

The percentage of the clinical students who were told by their dentists that they carried out accurate tooth brushing (51\%) was significantly higher $(P<.001)$ than the preclinical students (33\%).

Table 3. Percentage of 'agree' response according to the level of education.

\begin{tabular}{|c|c|c|c|c|}
\hline $\begin{array}{l}\text { HU-DBI } \\
\text { item No. }\end{array}$ & Preclinical & Clinical & Total & P-value* \\
\hline 1 & 74 & 74 & 74 & NS \\
\hline 2 & 25 & 13 & 21 & $P<.001$ \\
\hline 3 & 39 & 21 & 32 & $P<.001$ \\
\hline 4 & 22 & 19 & 21 & NS \\
\hline 5 & 14 & 14 & 14 & NS \\
\hline 6 & 30 & 10 & 23 & $\mathrm{P}<.001$ \\
\hline 7 & 25 & 13 & 21 & $P<.001$ \\
\hline 8 & 32 & 14 & 25 & $\mathrm{P}<.001$ \\
\hline 9 & 61 & 76 & 67 & $\mathrm{P}<.001$ \\
\hline 10 & 45 & 25 & 38 & $\mathrm{P}<.001$ \\
\hline 11 & 28 & 43 & 33 & $\mathrm{P}<.001$ \\
\hline 12 & 83 & 82 & 83 & NS \\
\hline 13 & 77 & 73 & 76 & NS \\
\hline 14 & 70 & 51 & 63 & $\mathrm{P}<.001$ \\
\hline 15 & 47 & 28 & 40 & $P<.001$ \\
\hline 16 & 24 & 40 & 30 & $P<.001$ \\
\hline 17 & 24 & 15 & 21 & $P<.01$ \\
\hline 18 & 32 & 17 & 27 & $\mathrm{P}<.001$ \\
\hline 19 & 30 & 29 & 30 & NS \\
\hline 20 & 33 & 51 & 40 & $P<.001$ \\
\hline 21 & 57 & 61 & 58 & NS \\
\hline 22 & 75 & 64 & 74 & NS \\
\hline 23 & 19 & 31 & 23 & $P<.001$ \\
\hline 24 & 14 & 18 & 15 & NS \\
\hline 25 & 22 & 33 & 26 & $P<.01$ \\
\hline 26 & 14 & 28 & 19 & $P<.001$ \\
\hline 27 & 20 & 32 & 24 & $\mathrm{P}<.001$ \\
\hline
\end{tabular}

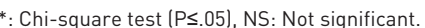

Nevermore, $40 \%$ of the dental students put off going to the dentist until they had a toothache although they reported low dental anxiety (Item 1, $74 \%$ ). Only a small percentage of the students had been told by their dentists that they brushed very well (Item 20, 40\%).

\section{Mean HU-DBI scores}

The mean HU-DBI score of the clinical students $(7.47 \pm 1.86)$ was significantly $(P<.001)$ higher than that of the preclinical students $(6.00 \pm 1.86)$. The overall mean score of the students was $6.53 \pm 2.00$ (Table 4).

\section{Logistic regression}

Table 5 shows the estimated coefficients and related statistics the logistic regression model that predicts the course of the origin. Interpretation of this analysis as follows: Preclinical students were more likely to brush with strong strokes, to use hard bristle toothbrush, to worry about the colour of their teeth, to think that they would have false teeth in future and daily brushing had no affect on their teeth and to seek dental care when the symptoms arise litems $3,6,8,10$, 14, 15, 17 and 18). Clinical dental students were more likely to receive good feedback about their brushing, to use dental floss, to clean their teeth without toothpaste and to smoke more than half pack per day (items 11, 20, 23 and 26).

\section{DISCUSSION}

Informing the patients about the correct oral habits and raising their awareness on how to prevent oral diseases are important accountabilities of oral health providers. Since dental students are the health professionals of the future, they must adopt accurate oral health attitudes and behaviour in their school years for directing their patients properly. In the Turkish dental faculties, preventive dentistry and periodontology courses are given in the first semester of the third year of education and students come in contact with patients in the second semester of the third year.

Table 4. Comparison of the HU-DBI scores between preclinical and clinical students.

\begin{tabular}{lcccc}
\hline & $\begin{array}{c}\text { Preclinical } \\
\text { (Mean } \pm \text { SD) }\end{array}$ & $\begin{array}{c}\text { Clinical } \\
\text { (Mean } \pm \text { SD) }\end{array}$ & $\begin{array}{c}\text { Total } \\
\text { (Mean } \pm S D \text { ) }\end{array}$ & P-value* \\
\hline HU-DBI score & $6.00 \pm 1.86$ & $7.47 \pm 1.86$ & $6.53 \pm 1.99$ & $<.001^{* *}$ \\
\hline
\end{tabular}

*: Mann Whitney U test P $\leq .05$ statistically significant. **: Between preclinical and clinical students. 
Since the questionnaire was distributed at the beginning of the academic years, only the students in their fourth and fifth year were designated as clinical students.

This is the first study among Turkish dental students comparing the oral health attitudes and behaviour in preclinical and clinical years. Although most of the previous results from different countries on dental students were only from a single dental faculty of a country ${ }^{12,19,24}$ in the present study, we included 3 old dental faculties from 2 different cities and the large number of students enabled us to make some possible general interpretations about the results. The results showed that the majority of dental students care about their oral health. Nevermore, low rate of regular dental visit among dental students can be explained by the fact that restorative dentistry is more commonly provided than preventive dentistry in the Turkish governmental dental health policy.

In accordance with the study from Jordan; ${ }^{23}$ the Turkish clinical students were also less often bothering by the colour of the gums, postponing going to the dentist until having a toothache, reporting gum bleeding after brushing, and more often brushing teeth twice daily or more than preclinical ones (Table 3). These improvements may due to the increasing experience of the students about oral health care by being in contact with patients in clinical environment. However, a study from India showed no significant differences between preclinical and clinical dental students. ${ }^{19}$

The questionnaire item 4 was to clear out the subjects' awareness about microbial dental plaque. But unexpectedly, clinical students who agreed with this item were at a lower percentage than preclinical students $19 \%$ and $22 \%$, respectively). It was probably because this question might also be misinterpreted as whether their teeth were clean or not instead of being aware of plaque. In some studies, this item was excluded from the questionnaire totally, ${ }^{23}$ or from calculation of the HU-DBI scores ${ }^{9}$ because of interpretation problems. Interestingly, there was no significant difference between preclinical and clinical dental students regarding daily brushing habits. Overall percentage of twice daily or more brushing of dental students was in accordance with previous results from Turkey and Jordan ${ }^{13,23}$ but higher than Iranian ones. ${ }^{7}$ Similar to the most of the previous studies, ${ }^{13,14,17,18,23}$ dental floss users were also low among Turkish dental students.

Smoking affects whole oral and systemic health. ${ }^{25-27}$ Dentists are important role models for their patients, and those using tobacco probably are less likely to counsel their patients to quite. In the present study, the rate of smoking was $26 \%$. The prevalence of smoking in this study was in accordance with previous studies on Turkish dental students where low number of dental students included (22\%). ${ }^{13} \mathrm{~A}$ review on smoking habits of

Table 5. Results of the logistic regression analysis for the level of education

\begin{tabular}{|c|c|c|c|c|c|c|}
\hline No & Item descriptions & B & SE & $\begin{array}{c}\text { Wald } \\
\text { Chi-square }\end{array}$ & df & $\mathrm{P}$ \\
\hline 3 & I worry about colour of my teeth & 0.621 & 0.203 & 9.392 & 1 & 0.002 \\
\hline 6 & I think that I cannot help having false teeth when I am old & 1.031 & 0.248 & 17.341 & 1 & 0.000 \\
\hline 8 & I think my teeth are getting worse despite my daily brushing & 0.713 & 0.230 & 9.617 & 1 & 0.002 \\
\hline 10 & I have never been professionally taught how to brush & 0.552 & 0.190 & 8.466 & 1 & 0.004 \\
\hline 11 & I think I can clean my teeth without using toothpaste & -0.545 & 0.187 & 8.527 & 1 & 0.003 \\
\hline 14 & It is impossible to prevent gum disease with toothbrushing alone & 0.615 & 0.178 & 11.961 & 1 & 0.001 \\
\hline 15 & I put off going to the dentist until I have a toothache & 0.350 & 0.187 & 3.512 & 1 & 0.041 \\
\hline 17 & I use a toothbrush which has hard bristles & 0.611 & 0.243 & 6.350 & 1 & 0.012 \\
\hline 18 & I don't feel l've brushed well unless I brush with strong strokes & 0.752 & 0.223 & 11.377 & 1 & 0.001 \\
\hline 20 & I have had my dentist tell me that I brush very well & -0.453 & 0.179 & 6.372 & 1 & 0.012 \\
\hline 23 & I use dental floss on regular basis everyday & -0.467 & 0.205 & 5.208 & 1 & 0.022 \\
\hline 26 & I smoke more than $1 / 2$ pack per day & -1.286 & 0.229 & 31.497 & 1 & 0.000 \\
\hline Constant & & -4.787 & 1.044 & 21.047 & 1 & 0.000 \\
\hline
\end{tabular}

Number of questions not included in this model $(1,4,5,12,13,19,21,22,24)$ since no significant difference was found between preclinical and clinical students in the Chisquare test analysis. 
dental students from 19 country was revealed that the prevalence of smoking among dental students was lower than of the population. ${ }^{28}$ In accordance with this, our result was lower than both general university students rate $(42.5 \%-49.4 \%)$ and population smoking rate (33.4\%). 29,30 The brushing teeth each tooth carefully with child-sized, hard bristle toothbrush and with strong strokes was statistically more common in smokers than nonsmokers $(P<.05)$. Moreover, the use of mouthwash was more prevalent among smokers. These may be because of worries about the staining effect of the smoking on teeth and about having malodour. Similar smoking rates were found among dental students in Bangladesh, Holland and Norway (22\%, 24\% and 24\%, respectively). ${ }^{28,31}$ However, the present smoking rate was lower than dental students in Greece (47\%), Serbia (43\%), Hungary (34\%), France (33\%) and Italy (\%33). ${ }^{28,31}$

Previous cross-cultural studies using the HU$\mathrm{DBI}$ in university settings gave us objective data about oral health behaviours of the students. Komabayashi et al ${ }^{11}$ noted that $18 \%$ of the British and $77 \%$ of the Chinese students were bothered by the colour of their gums and $72 \%$ of the British and $32 \%$ of the Chinese dental students were checking their teeth after brushing. In the present study, for the same items (Items 7 and 12), the percentages for the Turkish dental students were $21 \%$ and $83 \%$, respectively. In another cross-national study, 25\% of the Japanese and $45 \%$ of the Finnish dental students reported gum bleeding while toothbrushing 9 compared to the $21 \%$ of the students in our study.

The lectures on oral hygiene are given in the $3 r d$ year of the education. It was expected that all of the clinical students should know how to brush, so as to instruct their patients. Nevermore, 25\% of the clinical students still declared that they had never been taught professionally how to brush (Item 10). Maybe that's because the students might not regarded their educators as dental professionals because of having oral hygiene instructions in a lecture in the school but not in their personal dental visit.

The mean HU-DBI score of the clinical students was significantly higher the than the preclinical ones $(7.47 \pm 1.86$, and $6.00 \pm 1.86$, respectively) (Table 4). In contrast to our result, the study from Indian dental students showed no difference between the clinical and the preclinical students regarding to their $\mathrm{HU}-\mathrm{DBI}$ scores. ${ }^{19}$ In both preclinical and clinical years, the scores of the Turkish dental students were higher than their Indian pairs. The total HU-DBI score of the Turkish dental students was $6.53 \pm 1.99$. This was higher than Indian $^{19}$ (6.06 \pm 1.71 ) and Chinese ${ }^{11}$ (5.07) dental students, but lower than British ${ }^{11}$ (7.33), Greek ${ }^{32}$ $(6.86 \pm 1.83)$, and Japanese ${ }^{32}(7.40 \pm 2.55)$ ones. In the limitations of the study population, Turkey seems to lie between Eastern and Western countries in oral health attitudes and behaviour.

\section{CONCLUSIONS}

Turkish dental students had rather low oral health awareness in the beginning of their dental education. Oral health behaviour and attitudes improved significantly in the fourth and fifth years dental education. To serve as a good model for their patients, friends and family members the improvement should be much higher. To prove this, the preventive dentistry and periodontology courses should be started from the first year of dental education. Further clinical studies are needed for determining the correlation between the self-report and the intraoral clinical status of dental students.

\section{ACKNOWLEDGEMENTS}

The authors wish to thank Dr. Ahu Uraz, Gazi University, Faculty of Dentistry, Department of Periodontology, for achieving the data from Gazi University.

\section{REFERENCES}

1. Lin HC, Wong MC, Wang ZJ, Lo EC. Oral health knowledge, attitudes, and practices of Chinese adults. J Dent Res 2001;80:1466-1470.

2. Paik DI, Moon HS, Horowitz AM, Gift HC, Jeong KL, Suh SS. Knowledge of and practices related to caries prevention among Koreans. J Public Health Dent 1994;54:205-210.

3. Okada M, Kawamura M, Kaihara Y, Matsuzaki Y, Kuwahara $\mathrm{S}$, Ishidori $\mathrm{H}$, et al. Influence of parents' oral health behaviour on oral health status of their school children: an exploratory study employing a causal modelling technique. Int J Paediatr Dent 2002;12:101-108.

4. Okada M, Kawamura M, Hayashi Y, Takase N, Kozai K. Simultaneous interrelationship between the oral health behavior and oral health status of mothers and their children. J Oral Sci 2008;50:447-452. 
5. Levin L, Shenkman A. The relationship between dental caries status and oral health attitudes and behavior in young Israeli adults. J Dent Educ 2004;68:1185-1191.

6. Freeman R. The psychology of dental patient care. 5 . The determinants of dental health attitudes and behaviours. $\mathrm{Br}$ Dent J 1999;187:15-18.

7. Khami MR, Virtanen JI, Jafarian M, Murtomaa H. Oral health behaviour and its determinants amongst Iranian dental students. Eur J Dent Educ 2007;11:42-47.

8. Kawamura M. Dental behavioral science. The relationship between perceptions of oral health and oral status in adults. Hiroshima Daigaku Shigaku Zasshi 1988;20:273-286.

9. Kawamura M, Honkala E, Widstrom E, Komabayashi T. Cross-cultural differences of self-reported oral health behaviour in Japanese and Finnish dental students. Int Dent $J$ 2000;50:46-50.

10. Kawamura M, Spadafora A, Kim KJ, Komabayashi T. Comparison of United States and Korean dental hygiene students using the Hiroshima university-dental behavioural inventory(HU-DBI). Int Dent J 2002;52:156-162.

11. Komabayashi T, Kwan SY, Hu DY, Kajiwara K, Sasahara H, Kawamura M. A comparative study of oral health attitudes and behaviour using the Hiroshima University - Dental Behavioural Inventory (HU-DBI) between dental students in Britain and China. J Oral Sci 2005;47:1-7.

12. Kawamura M, Yip HK, Hu DY, Komabayashi T. A cross-cultural comparison of dental health attitudes and behaviour among freshman dental students in Japan, Hong Kong and West China. Int Dent J 2001;51:159-163.

13. Peker I, Alkurt MT. Oral health attitudes and behavior among a group of Turkish dental students. Eur J Dent 2009;3:24-31.

14. Al-Omari QD, Hamasha AA. Gender-specific oral health attitudes and behavior among dental students in Jordan. $J$ Contemp Dent Pract 2005;6:107-114.

15. Farsi JM, Farghaly MM, Farsi N. Oral health knowledge, attitude and behaviour among Saudi school students in Jeddah city. J Dent 2004;32:47-53.

16. Kawamura M, Takase N, Sasahara H, Okada M. Teenagers' oral health attitudes and behavior in Japan: comparison by sex and age group. J Oral Sci 2008;50:167-174.

17. Ostberg AL, Halling A, Lindblad U. Gender differences in knowledge, attitude, behavior and perceived oral health among adolescents. Acta Odontol Scand 1999;57:231-236.

18. Tada A, Hanada N. Sexual differences in oral health behaviour and factors associated with oral health behaviour in Japanese young adults. Public Health 2004;118:104-109.

19. Dagli RJ, Tadakamadla S, Dhanni C, Duraiswamy P, Kulkarni S. Self reported dental health attitude and behavior of dental students in India. J Oral Sci 2008;50:267-272.
20. Doḡan B, Küçükdogan Ü. Gender-specific oral health attitudes and behaviour among dental students (in Turkish). GÜ Diş Hek Fak Derg 2009;26:87-93.

21. Rong WS, Wang WJ, Yip HK. Attitudes of dental and medical students in their first and final years of undergraduate study to oral health behaviour. Eur J Dent Educ 2006;10:178184.

22. Sharda AJ, Shetty S. A comparative study of oral health knowledge, attitude and behaviour of first and final year dental students of Udaipur city, Rajasthan, India. Int J Dent Hyg 2008;6:347-353.

23. Barrieshi-Nusair K, Alomari Q, Said K. Dental health attitudes and behaviour among dental students in Jordan. Community Dent Health 2006;23:147-151.

24. Polychronopoulou A, Kawamura M, Athanasouli T. Oral selfcare behavior among dental school students in Greece. $J$ Oral Sci 2002;44:73-78.

25. Millar WJ, Locker D. Smoking and oral health status. J Can Dent Assoc 2007;73:155.

26. Johnson N. Tobacco use and oral cancer: a global perspective. J Dent Educ 2001;65:328-339.

27. Ezzati M, Lopez AD. Estimates of global mortality attributable to smoking in 2000. Lancet 2003;362:847-852.

28. Tobacco use and cessation counseling--global health professionals survey pilot study, 10 countries, 2005. MMWR Morb Mortal Wkly Rep 2005;54:505-509.

29. Erdogan N, Erdogan I. Smoking at school: views of Turkish university students. Int $J$ Environ Res Public Health 2009;6:36-50.

30. Oksuz E, Mutlu ET, Malhan S. Characteristics of daily and occasional smoking among youths. Public Health 2007;121:349-356.

31. Smith DR, Leggat PA. An international review of tobacco smoking among dental students in 19 countries. Int Dent J 2007;57:452-458.

32. Polychronopoulou A, Kawamura M. Oral self-care behaviours: comparing Greek and Japanese dental students. Eur J Dent Educ 2005;9:164-170. 